\title{
Decolorization of brilliant green dye using immersed lamp sonophotocatalytic reactor
}

\author{
Vitthal L. Gole ${ }^{1,2} \cdot$ Astha Priya $^{1} \cdot$ Sanjay P. Danao ${ }^{1}$
}

Received: 20 January 2017/ Accepted: 10 March 2017/Published online: 24 March 2017

(C) The Author(s) 2017. This article is an open access publication

\begin{abstract}
The textile and dye industries require an enormous amount of water for processing and produce a large volume of wastewater. Generated wastewater had potential hazards and a threat to the aquatic biota. The present work investigates the decolorization of brilliant green dye using a combination of two advanced oxidation techniques viz sonocatalysis and photocatalysis (immersed lamp) known as sonophotocatalysis ( $3 \mathrm{~L}$ capacity). The efficiency of decolorization is further improved in the presence of various additives viz. copper oxide, zinc oxide, and sodium chloride. The maximum decolorization of brilliant green (BG) (94.8\% in $120 \mathrm{~min}$ ) obtained in the presence of zinc oxide. The total organic carbon of the treated samples was measured to monitor complete mineralization of BG. The sonophotocatalytic process (in the presence of zinc oxide) shows maximum mineralization. Synergic combination of two oxidation processes increased the production of oxidizing radicals. Continuous cleaning of catalyst surface (due to sonolysis effect) improves the activity of the catalyst for photolysis operation. The present work is highly useful for the development of a sonophotocatalytic process.
\end{abstract}

Keywords Sonophotocatalysis - Brilliant green dye . Decolorization · Sonocatalysis · Photocatalysis

Vitthal L. Gole

vitthalgole@gmail.com

1 Department of Chemical Engineering, AISSMS College of Engineering, Kennedy Road, Pune, Maharashtra 411001, India

2 Department of Material Science and Engineering, The University of Arizona, P.O. Box 210012, Tucson, AZ, USA

\section{Introduction}

Textile and dye industries are considered as the second largest water consuming industries after the agricultural sector. The high amount of water was consumed during the processing, finishing and cleaning operations (Gogate and Bhosale 2013; Elsayed 2015). In textile industries, the massive amount of wastewater are generated during production and application of dye. Generated wastewater has high initial chemical oxygen demand (COD) in the range of $3000-4000 \mathrm{mg} / \mathrm{L}$. These is a major threat to ecology and aquatic biota (Gole and Gogate 2014; Sood et al. 2015). Conventional biological methods have limitations to treat the high level of COD (Khuntia et al. 2015; Dong et al. 2015; Raval et al. 2016). Advanced oxidation processes were found to be more efficient for the treatment of elevated levels of COD (Shambharkar and Chowdhury 2016).

Advanced oxidation processes such as sonolysis and photolysis are useful for the treatment of high initial concentration of COD (Hinge et al. 2016). The sonochemical effect is cavitational phenomena based on ultrasound interaction with aqueous liquid medium, when ultrasound passed through the liquid medium cycles of compression and rarefaction are developed. These cycles induced the cavitational bubble which expands and compresses before the collapse at million locations in the reactor. The higher temperature (4000-5000 K) and pressure (1000-50,000 bars) conditions reach inside the bubble cavity before collapsing (Gogate and Bhosale 2013; Gole and Gogate 2014; Shambharkar and Chowdhury 2016). These conditions are highly useful for enhancing the rate of chemical processing. During cavitation cycle, reactions are occurring at the three zones: (a) inside the cavity of the bubble, (b) at the interface of gas-liquid, and (c) radicals generated after the collapse of the cavity. (Sathishkumar et al. 2016; 
Marković et al. 2015; Ahmedchekkat et al. 2011, Bokhale et al. 2014). When UV light (photocatalysis) passes through the aqueous solution, the holes $\left(\mathrm{h}^{+}\right)$and electrons $\left(\mathrm{e}^{-}\right)$are generated. These generated holes and electrons can trap the pollutant on the actives site on the catalyst surface (Ertugay and Acar 2014; Kumar et al. 2015). The efficiency of photocatalysis process depends on the formation of hydroxyl radicals or the number of active sites in an aqueous medium and subsequent reaction between the hydroxyl radicals and targeted pollutants (Bhaskar et al. 2016; Dalbhanjan et al. 2016). The efficiency of photocatalysis process depends on the position of the UV lamp. Most of work reported in the literature on distributed type of lamp position photoreactor. A major limitation such a photoreactor is a part of the reactor volume expose to UV radiation. Perforation of UV irradiation is limited to few millimeters' in the aqueous liquid. To overcome these limitations, immersed lamp position type photocatalytic reactor is recommended for increasing perforation depth of UV light (Anju et al. 2012; Bouanimba et al. 2015). The significant shortfall with both oxidation processes is a local concentration of irradiation effect. (Hinge et al. 2016; Bhaskar et al. 2016; Dalbhanjan et al. 2016). The combined effects of sonocatalysis and photocatalysis (sonophotocatalysis) are useful for increasing the production of oxidation radicals. Another advantage of sonophotocatalysis and continuous cleaning of catalyst surface (sonochemical effect) increased the operational efficiency of the process.

The present work investigates the decolorization of brilliant green $(\mathrm{BG})$ dye using sonophotocatalytic reactor. This dye is commonly used for various applications, typically in paper industries (Ertugay and Acar 2014; Kumar et al. 2015; Anju et al. 2012). BG is highly toxic and recalcitrant compound and it poses a danger to human and aquatic biota due to mutagenic and carcinogenic effects (Sood et al. 2015; Khuntia et al. 2015; Shambharkar and Chowdhury 2016; Raval et al. 2016). Degradation of BG dye using photocatalysis (distributed lamp position) and sonocatalysis has been well studied and reported in the literature. Some works reported on the treatment of BG using nanocatalysts such as cerium oxide ( $\mathrm{Li}$ et al. 2016), $\mathrm{WO}_{3}$ (Kim et al. 2016) and C60 nanowhiskers (Park et al. 2016). Other studies reported on $\mathrm{TiO}_{2}-\mathrm{SiO}_{2}$ nanocomposites (Dong et al. 2015), $\mathrm{TiO}_{2}-\mathrm{Sr}$ (Sood et al. 2015), peat and natural zeolite-based solid composite (Elsayed 2015) and silver tin sulfide (Shambharkar and Chowdhury 2016). Studies on the degradation of BG using a combination of additives $\left(\mathrm{H}_{2} \mathrm{O}_{2}, \mathrm{Na}_{2} \mathrm{~S}_{2} \mathrm{O}_{8}\right.$, and $\left.\mathrm{NaOCl}\right)$ with hydrodynamic cavitation and acoustic cavitation reported that cavitational yield of BG was more for a combination of hydrodynamic cavitation with chemical oxidation compared to a combination of acoustic cavitation with chemical oxidation (Gogate and Bhosale 2013). Gole and Gogate (2014) stated that the sequential combination of sonochemical and microwave effects was found to be more efficient for degradation of BG. The degradation of BG using ozone microbubble reported maximum degradation in $30 \mathrm{~min}$ (Khuntia et al. 2015). Most of the studies on the treatment of BG reported using the single effect of sonolysis, photolysis or chemical oxidation in the presence of a catalyst and few volume of operations. The present work investigates the combination of oxidation process based on photocatalysis and sonocatalysis for $3 \mathrm{~L}$ capacity. The study also explored the effect of catalysts on the cavitational activity and a photocatalyst activity in the presence of copper oxide and zinc oxide. The effect of change in the properties of an aqueous medium by adding salt $(\mathrm{NaCl})$ was investigated. The total organic carbon was measured by analyzing the mineralization of dye and its intermediates.

\section{Materials and methods}

\section{Materials}

Brilliant Green (purity $\geq 90 \%$ ) dye was procured from M/s K. C. Medicals, Pune, India. Reagents used for experimental studies are zinc oxide (assay $\geq 99 \%$ ), copper oxide (assay $\geq 95 \%$ ) and sodium chloride (assay $\geq 99.5 \%$ ) (all reagents are Merck made). These reagents were obtained from a local supplier Pune, India. All reagents and chemicals were used as received from vendors without any purification or further treatment. A standard stock solution of known concentration of brilliant green dye (BG) was prepared by dissolving solid particles of BG dye in distilled water. Distilled water was obtained from the water distillation unit at AISSMS College of Engineering, Pune, India.

\section{Reactor configuration}

Schematic of sonophotocatalytic reactor used in present work is shown in Fig. 1. Sonochemical experiments were performed in an ultrasonic bath procured from M/s Oscar Electronics, Mumbai, India. Bath inner dimension is $25 \mathrm{~cm} \times 17.7 \mathrm{~cm} \times 9 \mathrm{~cm}$, electric power input is $120 \mathrm{~W}$, fixed frequency of operation is $20 \mathrm{kHz}$ and volume of the bath is $3.5 \mathrm{~L}$. Three transducers attached at the bottom of the reactor with triangular pitch arrangement. Actual power was dissipated into the reactor obtained from the calorimetric result (power: $43.9 \mathrm{~W} \sim 36.6 \%$ and volume: $3 \mathrm{~L}$ ). In photocatalysis experiments, two UV lamps were placed in glass cavity at a distance of $2 \mathrm{~cm}$ away from the adjacent wall and $2 \mathrm{~cm}$ from the bottom of the ultrasonic bath. The diameter of the glass is $5.5 \mathrm{~cm}$ and made of borosilicate (purity $\geq 88 \%$, glass has the similar property of quartz, and 


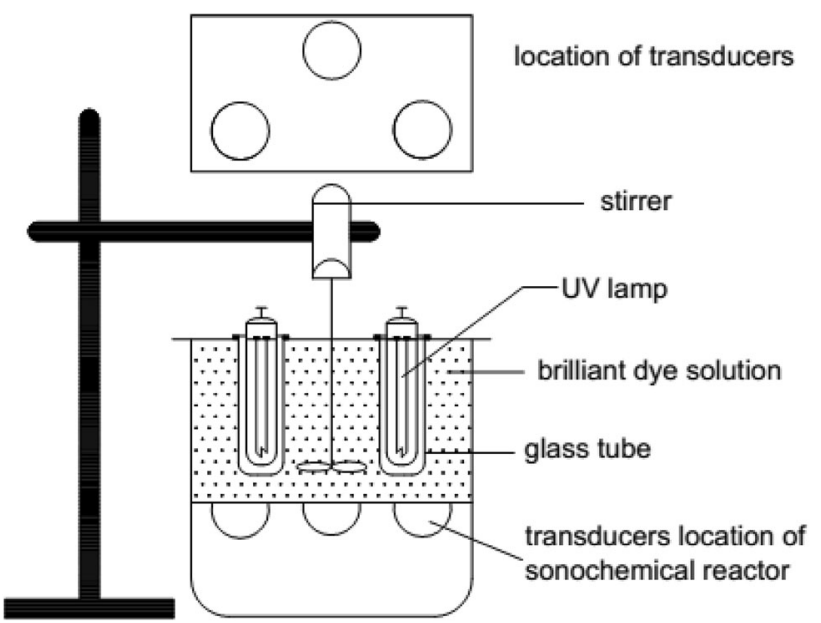

Fig. 1 Schematic of sonophoto reactor for treatment of brilliant green dye (BG)

there is a marginal attenuation of the sound wave). Specifications of lamps are dimension: $5 \mathrm{~cm} \times 5 \mathrm{~cm} \times 7 \mathrm{~cm}$, power: $5 \mathrm{~W}$, frequency: $50 \mathrm{~Hz}$, voltage: $220-240 \mathrm{~V}$, Luminous flux: $220 \mathrm{Lm}$. The wavelength range of UV source is $350-450 \mathrm{~nm}$ with a prominent peak at $365 \mathrm{~nm}$. The distance between the two lamps was $8 \mathrm{~cm}$ and placed on the wooden kart. The wooden kart was wrapped with aluminum foil to avoid UV radiations. Sonocatalytic experiments performed by keeping only ultrasonic bath 'on' mode, for photocatalytic experiments only UV lamps were 'on' mode, and for sonophotocatalytic experiments both ultrasound bath and UV lamps were 'on' mode. A blade type stirrer was introduced at the center of bath and $2 \mathrm{~cm}$ above from the bottom of the bath. Stirrer was used to maintain the homogeneity, suspension of heterogeneous catalyst/additives and uniform sonochemical and photochemical effects. The stirring speed was operated at a constant 400 RPM for all experiments.

\section{Experimental procedure}

A stock solution of $20.8 \mu \mathrm{M}$ concentration of BG dye was prepared by dissolving BG dye in distilled water. Initially, reactor was filled with $3 \mathrm{~L}$ of BG dye solution and catalyst was added. All the experiments were performed at the natural $\mathrm{pH}$ of the solution. The solution was stirred for $10 \mathrm{~min}$ at $400 \mathrm{rpm}$ to dissolve the BG dye and solid particles of additives such as sodium chloride. Constant reactor temperature of $25 \pm 2{ }^{\circ} \mathrm{C}$ was maintained by running the bath in the cyclic operation mode of 'on' and 'off.' Samples were withdrawn at $10 \mathrm{~min}$ interval of time and quenched immediately in an ice bath to stop the rate of decolorization of BG dye. The results of quenched samples compared with an instant analysis. The results analysis by both methods were nearly same with a standard deviation of $0.3 \mu \mathrm{M}$ (Hinge et al. 2016; Bhaskar et al. 2016). The change in $\mathrm{pH}$ during experiment was not measured. However, degradation of $\mathrm{BG}$ released the sulfate group $\left(\mathrm{SO}_{4}{ }^{2-}\right)$ and lowered the $\mathrm{pH}$ of the solution ( $\mathrm{Li}$ et al. 2016).

$\mathrm{BG}$ dye is one of the azo dyes consisting of azo $(-\mathrm{N}=\mathrm{N}-$ ) and sulfate $\left(\mathrm{SO}_{4} \mathrm{H}^{-}\right)$group and is highly soluble in water $(100 \mathrm{mg} / \mathrm{L})($ Sood et al. 2015). Decolorization efficiency of the dye depends on the cleavage of the azo group from the aromatic rings. The experiments were performed for decolorization of BG dye using sonocatalysis (US), photocatalysis (UV) and sonophotocatalysis (US-UV) in the presence/absence of additives. The optimized condition results are presented in Table 1 . These results are discuss with an objective of exploring the efficacy of synergy of the combination of US-UV.

\section{Analytical procedure}

The collected samples at a variable interval of time were filtered using filter papers of $0.45 \mu \mathrm{M}$ size (Make: Millipore) to remove the traces of solid particles. The progress of decolorization of $\mathrm{BG}$ dye was monitored using double beam spectrophotometer (Chemito SPECTROSCAN UV $2600)$ at fixed wavelength $(\lambda)$ of $663 \mathrm{nM}$. The calibration curve was obtained by preparing the standard solutions of a different concentration of a range of 1-50 ppm followed by analysis using a spectrophotometer. The concentration of carbon remaining after the treatment was measured by total organic carbon analyzer (TOC). Shimadzu TOC (Model: TOCLCPH) analyzer was used to monitor the concentration of carbon of the samples collected at optimizing conditions. The procedure for measurement of TOC was reported in the literature (Freire et al. 2015).

\section{Results and discussion}

\section{Effect of US, UV, and US-UV}

The result of the influence of US, UV and US-UV on the removal of BG dye is shown in Fig. 2. Result trends indicated that the concentration of BG dye decrease with time. The linear decrease in concentration of BG observed in initial phase of $60 \mathrm{~min}$ of operation. The further decrease in concentration with time was marginal compare to the initial phase of degradation study. The maximum decrease in concentration of BG was observed for US-UV compared to the US and UV. Removing moles of BG for US-UV was greater than the sum of total moles removed from UV and US. Moles of BG remaining after $120 \mathrm{~min}$ of treatment were $13.4 \mu \mathrm{M}(35.6 \%$ removal $), 14.9 \mu \mathrm{M}$ (28.3\% removal) and $8.2 \mu \mathrm{M}$ (60.3\% removal) for US, UV, and US-UV, respectively. Results clearly indicate that 
Table 1 Optimized parameters for degradation of brilliant green dye

\begin{tabular}{|c|c|c|c|c|}
\hline Additive & Additive concentration, $\mathrm{g} / \mathrm{L}$ & $\%$ degradation & Rate constant $\times 10^{-2}, \mathrm{~min}^{-1}$ & $\%$ TOC removal \\
\hline \multicolumn{5}{|l|}{ Sonocatalysis (US) } \\
\hline No additive & - & $35.6 \pm 1.8$ & $7.5 \pm 0.8$ & $10.1 \pm 0.4$ \\
\hline Copper oxide & 3 & $85.8 \pm 3.7$ & $17.7 \pm 1.7$ & $22.4 \pm 1.2$ \\
\hline Zinc oxide & 2 & $81.0 \pm 4.3$ & $21.6 \pm 1.8$ & $26.3 \pm 1.2$ \\
\hline Sodium chloride & 2 & $83.7 \pm 3.6$ & $22.3 \pm 1.9$ & $20.6 \pm 1.1$ \\
\hline \multicolumn{5}{|l|}{ Photocatalysis (UV) } \\
\hline No additive & - & $28.3 \pm 1.4$ & $3.3 \pm 0.3$ & $6.8 \pm 0.6$ \\
\hline Copper oxide & 3 & $64.8 \pm 2.3$ & $9.8 \pm 0.6$ & $13.2 \pm 0.8$ \\
\hline Zinc oxide & 2 & $72.3 \pm 3.5$ & $15.9 \pm 1.5$ & $18.9 \pm 1.6$ \\
\hline Sodium chloride & 2 & $54.8 \pm 1.4$ & $7.9 \pm 0.8$ & $12.3 \pm 0.9$ \\
\hline \multicolumn{5}{|c|}{ Sonophotocatalysis (US-UV) } \\
\hline No additive & - & $60.3 \pm 1.8$ & $9.3 \pm 1.1$ & $18.8 \pm 0.8$ \\
\hline Copper oxide & 3 & $74.8 \pm 2.2$ & $14.2 \pm 1.3$ & $28.3 \pm 1.3$ \\
\hline Zinc oxide & 2 & $94.8 \pm 4.8$ & $30.8 \pm 3.2$ & $38.8 \pm 2.3$ \\
\hline Sodium chloride & 2 & $65.2 \pm 2.3$ & $10.1 \pm 0.9$ & $23.6 \pm 1.3$ \\
\hline
\end{tabular}

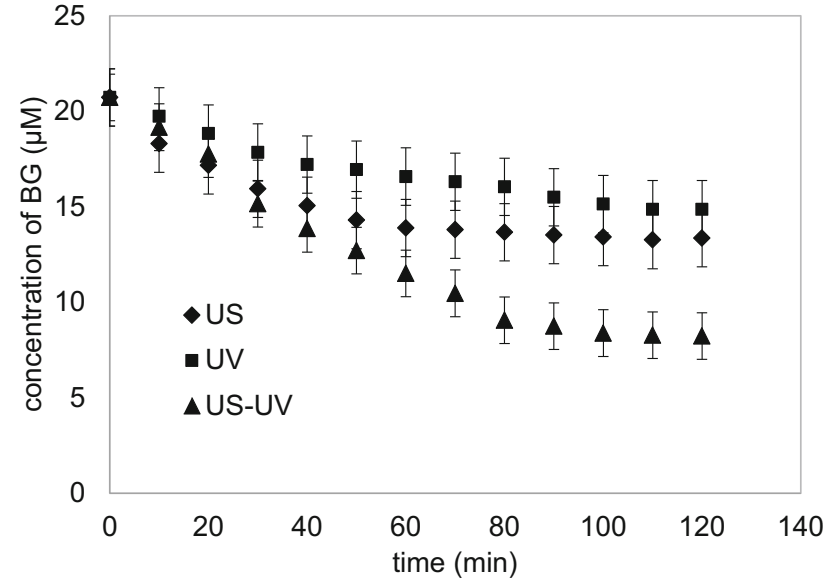

Fig. 2 Change in concentration of brilliant green dye (BG) with respect to time (initial concentration BG: $20.8 \mu \mathrm{M}$, initial $\mathrm{pH}$ of the solution: natural $\mathrm{pH}$ of $\mathrm{BG}$, frequency: $20 \mathrm{kHz}$, US power: $120 \mathrm{~W}$, UV power: $8 \mathrm{~W}$, stirring: $400 \mathrm{rpm}$ )

decolorization of BG was maximum for US-UV operation. Decolorization of BG dye depends on the removal of azo and sulfate groups from the aromatic rings. Cleavage of these groups increases with the oxidation reaction between these groups with oxidation radicals (Gogate and Bhosale 2013; Khuntia et al. 2015). The formation of the hydroxyl radicals during the sonochemical process depends on the cavitational activity or numbers of cavitation event per unit volume of solutions. Hydroxyl radicals were formed by pyrolysis mechanism of breaking the bond between the hydrogen and hydroxyl ions. It increases with the number of the transient collapse of the cavitational bubble (Reddy et al. 2016). During photolysis, photon released from the
UV source is absorbed by the water molecule and breaks the bond between the $\mathrm{H}$ and $\mathrm{OH}$ ions. Production of hydroxyl radicals during sonolysis depends on the liquid physiochemical properties of an aqueous medium, such as vapor pressure and surface tension (Bokhale et al. 2014). Decolorization of BG enhanced on the multifold basis for the synergic combination of US-UV. This multi-fold increase in degradation is due to increase in the concentration of hydroxyl radicals and subsequent reactions between hydroxyl radicals with targeted pollutants (Ahmedchekkat et al. 2011).

The obtained results were closely related to the literature-reported work. Sonophotolysis degradation of naphthol-blue dye stated that decolorization efficiency was more for US-UV combination $(\sim 3 \%)$ compared to sonolysis $(\sim 2 \%)$ and photolysis $(\sim 1 \%)$ for an initial concentration of naphthol blue-black as $10 \mathrm{mg} / \mathrm{L}$ and $\mathrm{pH}$ as 6.8. Higher decolorization rate for US-UV is due to increased in the concentration of hydroxyl ions for US-UV effect compared to effect UV or US alone (Reddy et al. 2016).

\section{Effect of copper oxide}

Copper oxide is considered as the most effective oxidation catalyst for promoting ultrasonic cavitational events. During sonication, tiny amounts of copper oxide particles act as nuclei sources for increasing the cavitational activity. These tiny molecules are further fragmented into smaller particles and created an additional source of increasing the cavitational activity (Kumar et al. 2015). Selection of optimum concentration of solid particle is essential because 
at higher concentration of solid particles may decrease the degradation rate due to the scattering effects and attenuation of incident sound energy. Photocatalytic activity depends on the optimum of the concentration of catalyst loadings (Anju et al. 2012). Optimum concentration for decolorization of BG was 3, 3 and $2 \mathrm{~g} / \mathrm{L}$ for US, UV, and US-UV, respectively, and results of decolorization of BG are shown in Fig. 3. Results indicate that decolorization of BG decreases linearly for first $90 \mathrm{~min}$ and the further increase was marginal. Moles of BG remaining (copper oxide concentration: $3 \mathrm{~g} / \mathrm{L}$ ) after $120 \mathrm{~min}$ of treatment were $2.9 \mu \mathrm{M}$ (85.8\% removal), $7.3 \mu \mathrm{M}$ (64.8\% removal) and $5.2 \mu \mathrm{M}$ (74.8\% removal) for US, UV, and US-UV, respectively. The maximum decolorization rate was observed for US compared to UV and combination of USUV. Synergy effect of US and UV was not observed on decolorization of BG. Lower decolorization for US-UV may be due to scavenging effects of a combination of hydroxyl radicals to form hydrogen peroxide or other radicals (Ertugay and Acar 2014). The possible reduction of photocatalyst efficiency was due to the adsorption of contaminants on the catalyst surface which may block the active sites of the catalyst. Overall it can consider that copper oxide is a suitable catalyst for US compared to USUV and UV mode of operations (Marković et al. 2015; Ahmedchekkat et al. 2011). The results are consistent with the reported findings. The study of US-UV degradation of rhodamine $6 \mathrm{G}$ indicated that degradation increases with the addition of copper oxide; the maximum degradation of $52.6 \%$ was observed for $(1.5 \mathrm{~g} / \mathrm{L}$ loading of copper oxide) US-UV treatment and $26.4 \%$ for UV treatment at $12.5 \mathrm{pH}$ of the solution (Bokhale et al. 2014). Similar results reported for US-UV degradation of dye C.I. acid orange 7 in the presence of titanium dioxide reported that pseudo-

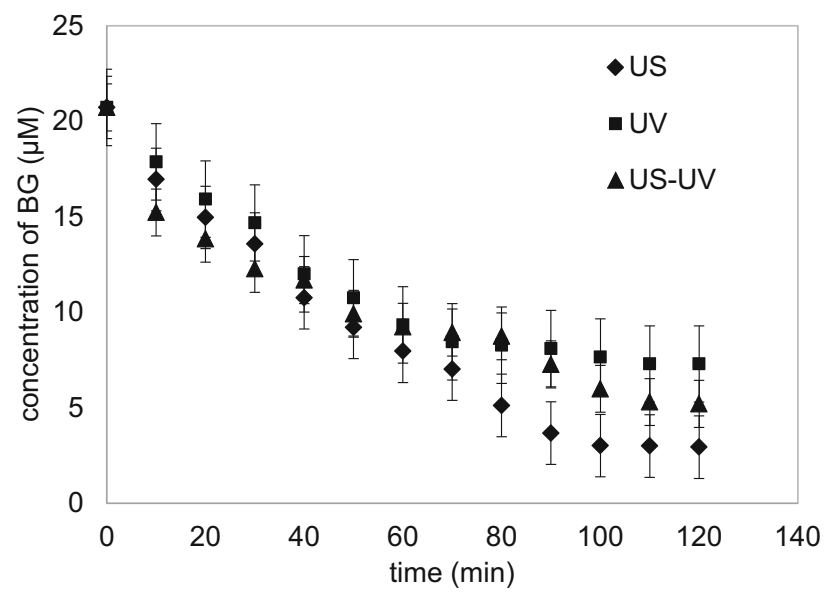

Fig. 3 Change in concentration of brilliant green dye (BG) in the presence of copper oxide (initial concentration BG: $20.8 \mu \mathrm{M}$, initial $\mathrm{pH}$ of the solution: natural $\mathrm{pH}$ of $\mathrm{BG}$, frequency: $20 \mathrm{kHz}$, US power: $120 \mathrm{~W}$, UV power: $8 \mathrm{~W}$, stirring: $400 \mathrm{rpm}$, concentration of copper oxide: $3 \mathrm{~g} / \mathrm{L}$ ) first-order rate constants were $1.54,3.38$ and $7.24 \mathrm{~min}^{-1}$ for US, UV and US-UV operations, respectively, and synergic index as 1.47 (Marković et al. 2015).

\section{Effect of zinc oxide}

Zinc oxide $(3.2 \mathrm{eV})$ has similar properties like $\mathrm{TiO}_{2}$ $(3.2 \mathrm{eV})$. It is considered as more stable photocatalyst compare to $\mathrm{TiO}_{2}$. It has several advantages over the $\mathrm{TiO}_{2}$ such as electron mobility of $\mathrm{ZnO}\left(\sim 100 \mathrm{~cm}^{2} \mathrm{~V}^{-1} \mathrm{~s}^{-1}\right)$ is twice that of $\mathrm{TiO}_{2}\left(>1 \mathrm{~cm}^{2} \mathrm{~V}^{-1} \mathrm{~s}^{-1}\right)$. The combined effects of sonophotocatalysis in the presence of zinc oxide increased the surface area for photocatalytic activity and provided additional nucleation growth for increasing the cavitational activities. Catalyst activity, and the surface area of catalyst (fragmentation of catalyst particles is due to US effects) were increased for combination effect of US and UV. Another advantage of US-UV is the continuous cleaning of catalyst surface (Ertugay and Acar 2014; Kumar et al. 2015; Anju et al. 2012). The increase in the population of hydroxyl radicals may lead to higher decolorization of BG. Sono decolorization of $\mathrm{BG}$ reaction scheme in the presence of zinc oxide is shown in Eqs. (2)(8) ( ')))' represents interaction of US with liquid medium):

$$
\begin{aligned}
& \left.\left.\left.\mathrm{H}_{2} \mathrm{O}+\right)\right)\right) \rightarrow \mathrm{OH}^{-}+\mathrm{H}^{-} \\
& \mathrm{OH}+\mathrm{OH}^{-} \rightarrow \mathrm{H}_{2} \mathrm{O}_{2} \\
& 2 \mathrm{OH} \rightarrow \mathrm{H}_{2} \mathrm{O}+\mathrm{O}^{-} \\
& \mathrm{ZnO}+\mathrm{H}^{-} \rightarrow \mathrm{Zn}^{2+}+\mathrm{H}_{2} \mathrm{O} \\
& \mathrm{Zn}^{2+}+2 \mathrm{OH} \rightarrow \mathrm{ZnO}+\mathrm{H}_{2} \mathrm{O} \\
& \mathrm{Zn}^{2+}+2 \mathrm{OH} \rightarrow \mathrm{Zn}(\mathrm{OH})_{2} \\
& \mathrm{Zn}(\mathrm{OH})_{2} \rightarrow \mathrm{ZnO}+\mathrm{H}_{2} \mathrm{O} \\
& \mathrm{Zn}^{2+}+2 \mathrm{O}_{2} \rightarrow \mathrm{ZnO}+3 / 2 \mathrm{O}_{2}
\end{aligned}
$$

Equations (1)-(3) show that during sonolysis, the net production of oxidation radical is much lower compared to oxidation radicals formed in the presence of zinc oxide (Eqs. 4-8). Excess production of oxidizing radicals in the presence of zinc oxide was highly useful for decolorization of BG. When zinc oxide is illuminated by the UV light (photons) and energy level of zinc oxide exceeds band gap energy to stimulate electron $\left(\mathrm{e}^{-}\right)$from the valence band to conduction band. Holes produced in the valance band excite due to shifting of an electron from valence band (Ertugay and Acar 2014). These holes and electrons produced from the photon energy interact with $\mathrm{H}_{2} \mathrm{O}$ or $\mathrm{OH}$ radicals to produce oxidation and hydroxyl radicals (Eqs. 9-15). These oxidants produce from photoexcitation in the presence of zinc oxide highly beneficial for decolorization of BG. 
$\mathrm{ZnO}+\mathrm{h} v \rightarrow \mathrm{OH}^{\cdot}+\mathrm{H}^{\cdot}$

$\mathrm{h}^{+}+\mathrm{H}_{2} \mathrm{O} \rightarrow \mathrm{ZnO}\left(\mathrm{e}^{-}+\mathrm{h}^{+}\right)$

$\mathrm{h}^{+}+\mathrm{H}_{2} \mathrm{O} \rightarrow \cdot \mathrm{OH}+\mathrm{H}^{+}$

$\mathrm{h}^{+}+\mathrm{OH}^{-} \rightarrow \cdot \mathrm{OH}$

$\mathrm{e}^{-}+\mathrm{O}_{2} \rightarrow \cdot \mathrm{O}_{2}^{-}$

$\mathrm{O}_{2}^{-}+\mathrm{H}_{2} \mathrm{O}+\mathrm{H}^{+} \rightarrow \mathrm{H}_{2} \mathrm{O}_{2}+\mathrm{OH}^{-}$

$\mathrm{H}_{2} \mathrm{O}_{2}+\mathrm{e}^{-} \rightarrow \cdot \mathrm{OH}+\mathrm{OH}^{-}$

Results for decolorization of BG in the presence of zinc oxide are shown in Fig. 4. The resulting trends show that decolorization of $\mathrm{BG}$ increases with an increasing time. During the initial phase of decolorization showing the linear correlation with time (up to $60 \mathrm{~min}$ ), a further increase in time shows the marginal decrease in concentration of BG. Decolorization rate was maximum for US-UV followed by US and UV, respectively. Concentration of $\mathrm{BG}$ for $120 \mathrm{~min}$ operation in the presence of $\mathrm{ZnO}(2 \mathrm{~g} / \mathrm{L})$ was $3.9 \mu \mathrm{M}$ (81.0\% removal), $5.8 \mu \mathrm{M}(72.3 \%$ removal) and $1.1 \mu \mathrm{M}(94.8 \%$ removal $)$ for US, UV and US-UV, respectively. The increase in decolorization of $\mathrm{BG}$ might be due to more active sites on the catalyst surface. The combination of US-UV is useful for the production of oxidation/hydroxyl radicals in the presence of zinc oxide and physical effects associated with US useful to clean the catalyst surface. Thus, more active sites are available for photoexcitation (Bokhale et al. 2014; Reddy et al. 2016). US-UV catalyzed is process useful for deagglomeration of catalyst particles. This effect may be useful for enhancing numbers active sites for photocatalysis process and more numbers of the additional sites for bubble defragmentation for sonocatalysis (Anju

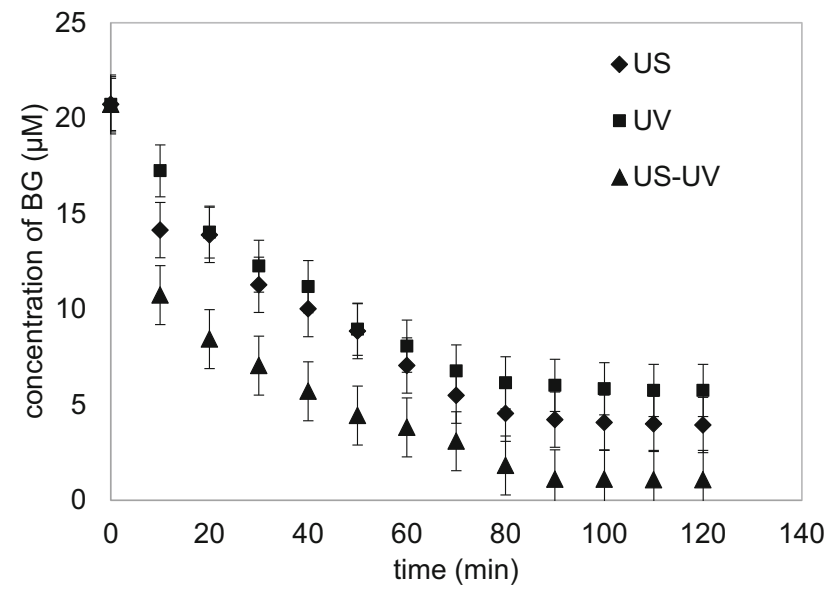

Fig. 4 Change in concentration of brilliant green dye (BG) in the presence of zinc oxide (initial concentration BG: $20.8 \mu \mathrm{M}$, initial $\mathrm{pH}$ of the solution: natural $\mathrm{pH}$ of $\mathrm{BG}$, frequency: $20 \mathrm{kHz}$, US power: $120 \mathrm{~W}$, UV power: $8 \mathrm{~W}$, stirring: $400 \mathrm{rpm}$, concentration of zinc oxide: $2 \mathrm{~g} / \mathrm{L}$ ) et al. 2012). Thus, there is multi-fold increased in hydroxyl radical's for US-UV effect compare to individual effects of US or UV. The recombination of these radicals (e.g., $\mathrm{OOH}$ ) lowered the oxidation potential (e.g., $\mathrm{OOH}$ ) compared to hydroxyl radicals. Thus, the combined effects of sonophotocatlysis do not show synergetic effects on the degradation of BG. Our results closely related to the reported work in the literature, sonophotocatalyzed degradation of direct blue 71 dye in the presence zinc oxide loading of $1 \mathrm{~g} / \mathrm{L}$ for UV and USUV process was 48 and $100 \%$, respectively. They reported that the optimal selection of catalyst loading is useful to avoid scattering of light and attenuation of ultrasound (Ertugay and Acar 2014).

\section{Effect of sodium chloride}

The addition of salt plays a vital and significant role in enhancing sonophotocatalytic decolorization rate of $\mathrm{BG}$. The results of moles of BG removal are shown in Fig. 5. Moles of BG remaining after $120 \mathrm{~min}$ in the presence of sodium chloride (concentration: $2 \mathrm{~g} / \mathrm{L}$ ) were $3.4 \mu \mathrm{M}$ (83.7\% removal), $9.4 \mu \mathrm{M}(54.7 \%$ removal) and $7.2 \mu \mathrm{M}$ (65.2\% removal) for US, UV, and US-UV, respectively. Decolorization of $\mathrm{BG}$ is more for US but less than the addition of copper oxide and zinc oxide. Removal trend of moles of BG clearly indicates that addition of salt does not show any additional benefit for increasing the decolorization rate of $\mathrm{BG}$. The addition of sodium chloride during sonication is beneficial. Salt changes the physiochemical properties, viz. vapor pressure; surface tension leads to change in partition coefficient of aqueous wastewater solution (Dalbhanjan et al. 2016). In the presence of

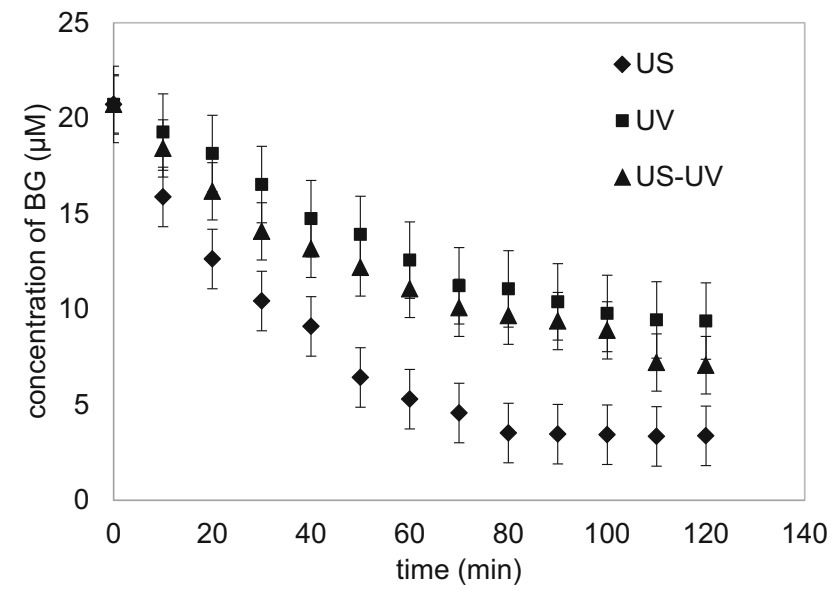

Fig. 5 Change in concentration of brilliant green dye (BG) in the presence of sodium chloride (initial concentration BG: $20.8 \mu \mathrm{M}$, initial $\mathrm{pH}$ of the solution: natural $\mathrm{pH}$ of $\mathrm{BG}$, frequency: $20 \mathrm{kHz}$, US power: $120 \mathrm{~W}$, UV power: $8 \mathrm{~W}$, stirring: $400 \mathrm{rpm}$, concentration of sodium chloride: $2 \mathrm{~g} / \mathrm{L}$ ) 
sodium chloride, the pollutant (US) present in bulk of solution pushes towards the interface of the bubble (Kumar et al. 2015). It helps to increase the contact between the hydroxyl radicals formed at gas-liquid interface and targeted pollutants. An additional benefit of the addition of salt increased in cavitational events, which may be useful for higher decolorization of BG (Reddy et al. 2016). Lower decolorization of $\mathrm{BG}$ may be due to the adsorption of the pollutant of the catalyst surface which may reduce the formation of hydroxyl radicals. The addition of salt does not increase active sites during photocatalytic process. Salt has a detrimental effect on UV absorption. Cations and anion of sodium chloride affect the degradation efficiency of $\mathrm{UV}$ process. $\mathrm{Cl}$ ion acts as the radical scavenger during the UV process and reduces absorption of ultraviolet radiations (Bhaskar et al. 2016; Dalbhanjan et al. 2016). Increase in decolorization of $\mathrm{BG}$ in the presence of $\mathrm{UV}$ (presence of sodium chloride) compared to UV (absence of catalyst) may be due to the beneficial effects of addition of salt, which may use for US process especially $\mathrm{Cl}$ ions. The presence of $\mathrm{Na}$ radicals may be useful for increasing the active sites in UV process (Bouanimba et al. 2015; Dong et al. 2015). Inhibition in the rate of decolorization has seen in the presence of chloride ion. It may be due to scavenging characteristics (hole) of chloride ion based on the following Eqs. (16)-(19):

$$
\begin{aligned}
& \mathrm{Cl}^{-}+\mathrm{h} v^{+} \rightarrow \mathrm{Cl}^{-} \\
& \mathrm{Cl}^{-}+\mathrm{Cl}^{-} \rightarrow \mathrm{Cl}_{2} \\
& \mathrm{Cl}^{-}+\cdot \mathrm{OH} \rightarrow \mathrm{HOCl}^{-} \\
& \mathrm{HOCl}^{-}+\mathrm{H}^{+} \rightarrow \mathrm{Cl}^{-}+\mathrm{H}_{2} \mathrm{O}
\end{aligned}
$$

Our results are consistent with the reported literature; the photocatalytic degradation of humic acid in the presence of sodium chloride reported that TOC removal was higher $(>90 \%)$ in the absence of sodium chloride for $240 \mathrm{~min}$ of operation. Sonophotocatalytic degradation of rhodamine $\mathrm{B}$ and rhodamine $6 \mathrm{G}$ in the presence of optimal loading of sodium chloride was 69 and $71 \%$, respectively (Bhaskar et al. 2016). Study on the removal of Rhodamine $6 \mathrm{G}$ using solar irradiations in the presence of maximum loading $1.5 \mathrm{~g} / \mathrm{L}$ of sodium chloride reported $45 \%$ of reduction of chemical oxygen demand (Dalbhanjan et al. 2016).

\section{Mineralization of BG}

BG consists of azo group, sulfate group, and an aromatic ring. The complete mineralization of BG depends on the oxidation of these groups and ring (Gogate and Bhosale 2013; Khuntia et al. 2015). Total organic carbon (TOC) removal was measured to monitor the mineralization of
BG. Results of TOC removal, cavitational yield, pseudofirst order rate constant and percentage of decolorization are shown in Table 1. TOC removal was maximum for US-UV operation compared to the effects of UV and US. The highest removal of TOC was observed for US-UV in the presence of zinc oxide; similar results were observed for the UV and US in the presence of copper oxide. Lower TOC removal observed for US followed UV in the presence of all catalyst. TOC removal for US-UV maximum to minimum in the presence of catalysts was zinc oxide $>$ copper oxide $>$ sodium chloride $>$ no catalyst. When the results were compared based on the pseudo-firstorder rate constant, the similar pattern of TOC removal was observed. The maximum pseudo-first-order rate constant was observed for US-UV in the presence of zinc oxide.

Efficacy of sonophotocatalytic reactor depends on the number of hydroxyl radicals and uniform distribution of these radicals in the reactor (Anju et al. 2012). These results confirm that zinc oxide acts as a photocatalyst for UV operation and enhances the surface cavitational activity for US. Thus, the production of cavitational events per volume in the reactor and formation of actives sites for the generation of hydroxyl radicals/oxygen radicals are more in the case of US-UV (the presence of zinc oxide). The number of oxidizing radicals required for complete mineralization of $\mathrm{BG}$ depends on the number of oxidizing radicals needed for degradation of $\mathrm{BG}$ and degradation of intermediate products formed during the oxidation of $\mathrm{BG}$ (Hinge et al. 2016; Bhaskar et al. 2016; Dalbhanjan et al. 2016). The common oxidation products of $B G$ are 4-dimethylamino-phenol, (3-dimethylamino-phenyl)-(4dimethylamino-phenyl)-methanone, phenol, 4-dimethylamino-benzoic acid, dimethyl-phenyl-amine, (3-aminophenyl)-phenyl-methanone, 4-amino-phenol, 3-aminobenzoic acid/4-amino-benzoic acid, aniline, oxalic acid, acetic acid, and acetamide. Complete degradation of these intermediates and BG depends on the physicochemical properties of the aqueous solution and the activity of these intermediate during the sonolysis and photolysis (Gogate and Bhosale 2013; Gole and Gogate 2014). Compounds with lower $\mathrm{pH}$ or $\mathrm{pKa}$ value attract towards the cavitational bubble or near the interface of the gas-liquid interface. Lower $\mathrm{pH}$ is also beneficial for the degradation of photocatalysis activity. At lower $\mathrm{pH}$, the molecules quickly dissociated into the ions and cations. These ions rapidly deposited on the surface of photocatalyst ( $\mathrm{Li}$ et al. 2016; Kim et al. 2016). Other factors also contributing to the degradation of BG are the intensity of radiation of UV light and uniform distribution of cavitational effects in the sonochemical reactor. The maximum absorption of UV radiations was improved by a selection of the location and position of UV light. UV light with immersed position was recommended for improving the distribution of light 
(Elsayed 2015; Sood et al. 2015). Degradation of BG using US-UV was found to be more efficient and has more potential for scale-up aspects.

\section{Conclusions}

The present work confirms the efficacy of sonophotocatalytic reactor for decolorization of $\mathrm{BG}$. Decolorization of BG was investigated using sonocatalysis (US), photocatalysis (UV) and sonophotocatalysis (US-UV) in the presence of a catalyst like copper oxide (enhancing surface cavitational and photocatalytic activity), zinc oxide (increases the photocatalysis activity) and sodium chloride (change the physicochemical properties of the liquid medium). Decolorization of BG depends on the number formation of oxidizing radicals. Sonophotocatalytic reactor has shown the maximum efficiency in the presence of zinc oxide. The maximum decolorization, TOC removal, and pseudo-first-order degradation rate constant were 94.8, 38.8 , and $30.8 \mathrm{~min}^{-1}$, respectively. Investigation of the present work indicates the potential applications of the immersed lamp sonophotocatalytic reactor for treatment of brilliant green dye.

Open Access This article is distributed under the terms of the Creative Commons Attribution 4.0 International License (http:// creativecommons.org/licenses/by/4.0/), which permits unrestricted use, distribution, and reproduction in any medium, provided you give appropriate credit to the original author(s) and the source, provide a link to the Creative Commons license, and indicate if changes were made.

\section{References}

Ahmedchekkat F, Medjram MS, Chihab M, Al-bsoul AMA (2011) Sonophotocatalytic degradation of rhodamine B using a novel reactor geometry: effect of operating conditions. Chem Eng J 178:244-251. doi:10.1016/j.cej.2011.10.061

Anju SG, Yesodharan S, Yesodharan EP (2012) Zinc oxide mediated sonophotocatalytic degradation of phenol in water. Chem Eng J 189-190:84-93. doi:10.1016/j.cej.2012.02.032

Bhaskar NS, Kadam AD, Biwal JJ, Diwate PM, Dalbhanjan RR, Mahale DD, Hinge SP, Banerjee BS, Mohod AV, Gogate PR (2016) Removal of rhodamine 6G from wastewater using solar irradiations in the presence of different additives. Desalin Water Treat 57:18275-18285. doi:10.1080/19443994.2015.1090923

Bokhale NB, Bomble SD, Dalbhanjan RR, Mahale DD, Hinge SP, Banerjee BS, Mohod AV, Gogate PR (2014) Sonocatalytic and sonophotocatalytic degradation of rhodamine 6G containing wastewaters. Ultrason Sonochem 21:1797-1804. doi:10.1016/j. ultsonch.2014.03.022

Bouanimba N, Laid N, Zouaghi R, Sehili T (2015) Effect of pH and inorganic salts on the photocatalytic decolorization of methyl orange in the presence of $\mathrm{TiO}_{2} \mathrm{P} 25$ and PC500. Desalin Water Treat 53:951-963. doi:10.1080/19443994.2013.848667

Dalbhanjan RR, Pande NS, Banerjee BS, Hinge SP, Mohod AV, Gogate PR (2016) Degradation of patent blue V dye using modified photocatalytic reactor based on solar and UV irradiations. Desalin Water Treat 57:18217-18228. doi:10.1080/ 19443994.2015.1090922

Dong W, Sun Y, Ma Q, Zhu L, Hua W, Lu X, Zhuang G, Zhang S, Guo Z, Zhao D (2015) Excellent photocatalytic degradation activities of ordered mesoporous anatase $\mathrm{TiO}_{2}-\mathrm{SiO}_{2}$ nanocomposites to various organic contaminants. J Hazard Mater 229-230:307-320. doi:10.1016/j.jhazmat.2012.06.002

Elsayed MA (2015) Ultrasonic removal of pyridine from wastewater: optimization of the operating conditions. Appl Water Sci 5:221-227. doi:10.1007/s13201-014-0182-x

Ertugay N, Acar FN (2014) The degradation of direct blue 71 by sono, photo, and sonophotocatalytic oxidation in the presence of $\mathrm{ZnO}$ nanocatalyst. Appl Surf Sci 318:121-126. doi:10.1016/j. apsusc.2014.01.178

Freire LR, Balachandran R, Alvarez RS, Keswani M (2015) Effect of sound frequency and initial concentration on the sonochemical degradation of perfluorooctane sulfonate (PFOS). J Hazard Mater 300:662-669. doi:10.1016/j.jhazmat.2015.07.077

Gogate PR, Bhosale GS (2013) Comparison of effectiveness of acoustic and hydrodynamic cavitation in combined treatment schemes for degradation of dye wastewaters. Chem Eng Process 71:59-69. doi:10.1016/j.cep.2013.03.001

Gole VL, Gogate PR (2014) Degradation of brilliant green dye using combined treatment strategies based on different irradiations. Sep Purif Technol 133:212-220. doi:10.1016/j.seppur.2014.07. 002

Hinge SP, Orpe MS, Sathe KV, Tikhe GD, Pandey NS, Bawankar KN, Bagal MV, Mohod AV, Gogate PR (2016) Combined removal of rhodamine $\mathrm{B}$ and rhodamine $6 \mathrm{G}$ from wastewater using novel treatment approaches based on ultrasonic and ultraviolet irradiations. Desalin Water Treat 57:23927-23939. doi:10.1080/19443994.2016.1143404

Khuntia S, Majumder SK, Ghosh P (2015) A pilot plant study of the degradation of brilliant green dye using ozone microbubbles: mechanism and kinetics of reaction. Environ Technol 36:336-347. doi:10.1080/09593330.2014.946971

Kim KH, Ko JW, Ko WB (2016) Preparation and kinetics of nanocomposites using $\mathrm{WO}_{3}$ with carbon nanomaterials for photocatalytic degradation of organic dyes. Asian $\mathrm{J}$ Chem 28:194-198. doi:10.14233/ajchem.2016.19338

Kumar R, Kumar G, Akhtar MS, Umar A (2015) Sonophotocatalytic degradation of methyl orange using $\mathrm{ZnO}$ nano-aggregates. J Alloy Compd 629:167-172. doi:10.1016/j.apsusc.2014.01.178

Li J, Ko JW, Ko WB (2016) Preparation and characterization of $\mathrm{CeO}_{2}-\mathrm{C} 60$ nanocomposites and their application to photocatalytic degradation of organic dyes. Asian J Chem 28:2020-2024. doi:10.14233/ajchem.2016.19880

Marković D, Šaponjić Z, Radoičić M, Radetić T, Vodnik V, Potkonjak B, Radetic M (2015) Sonophotocatalytic degradation of dye C.I. acid orange 7 by $\mathrm{TiO}_{2}$ and $\mathrm{Ag}$ nanoparticles immobilized on corona-pretreated polypropylene non-woven fabric. Ultrason Sonochem 24:221-229. doi:10.1016/j.ultsonch.2014.11.017

Park HS, Ko JW, Ko WB (2016) Preparation of C60 nanowhisker$\mathrm{Nb}_{2} \mathrm{O}_{5}$ nanocomposites and kinetics study of photocatalytic degradation of organic dyes. Asian J Chem 28:2769-2774. doi:10.14233/ajchem.2016.20117

Raval NP, Shah PU, Shah NK (2016) Malachite green "a cationic dye" and its removal from aqueous solution by adsorption. Appl Water Sci. doi:10.1007/s13201-016-0512-2

Reddy DR, Dinesh GK, Anandan S, Sivasankar T (2016) Sonophotocatalytic treatment of naphthol blue black dye and real textile wastewater using synthesized $\mathrm{Fe}$-doped $\mathrm{TiO}_{2}$. Chem Eng Process 99:10-18. doi:10.1016/j.cep.2015.10.019

Sathishkumar P, Mangalaraja RV, Anandan S (2016) Review on the recent improvements in sonochemical and combined 
sonochemical oxidation processes-a powerful tool for destruction of environmental contaminants. Renew Sust Energ Rev 55:426-454. doi:10.1016/j.rser.2015.10.139

Shambharkar BH, Chowdhury AP (2016) Ethylene glycol mediated synthesis of $\mathrm{Ag}_{8} \mathrm{SnS}_{6}$ nanoparticles and their exploitation in the degradation of eosin yellow and brilliant green. RSC Adv 6:10513-10519. doi:10.1039/C5RA25051J (Paper)
Sood S, Umarb A, Mehta SK, Sinhad ASK, Kansal SK (2015) Efficient photocatalytic degradation of brilliant green using Srdoped $\mathrm{TiO}_{2}$ nanoparticles. Ceram Int 41:3533-3540. doi:10. 1016/j.ceramint.2014.11.010 